\title{
Story Based Learning: A Student Centred Practice-Oriented Learning Strategy
}

Karen MacKinnon

School of Nursing, University of Victoria, kamackin@uvic.ca

Lynne E. Young

School of Nursing, University of Victoria, leyoung@uvic.ca

Follow this and additional works at: https://qane-afi.casn.ca/journal

Part of the Nursing Commons

\section{Recommended Citation}

MacKinnon, Karen and Young, Lynne E. (2014) "Story Based Learning: A Student Centred Practice-Oriented Learning Strategy," Quality Advancement in Nursing Education - Avancées en formation infirmière: Vol. 1: Iss. 1, Article 3. DOI: https://doi.org/10.17483/2368-6669.1000

This Article is brought to you for free and open access by Quality Advancement in Nursing Education - Avancées en formation infirmière. It has been accepted for inclusion in Quality Advancement in Nursing Education - Avancées en formation infirmière by an authorized editor of Quality Advancement in Nursing Education - Avancées en formation infirmière. 


\section{Story Based Learning: A Student Centred Practice-Oriented Learning Strategy}

\section{Cover Page Footnote}

We would like to acknowledge all the learners and teachers who have shared their experiences of SBL with us and who are continually striving for excellence in nursing education and practice. We would also like to thank Lippincott, Williams \& Wilkins for permission to reprint the SBL Model originally published in L.E. Young \& B.L. Paterson (Eds.). Teaching Nursing: Developing a student-centered learning environment (pp. 164-188). Philadelphia: Lippincott, Williams \& Wilkins. 
Story-based learning (SBL) was developed to promote both quality learning environments and quality nursing care. SBL is a student-centred learning strategy (pedagogical tool) grounded in a nursing perspective that was developed within a participatory process with faculty and students during its use in upper level courses in a Canadian baccalaureate nursing program (Young, 2007). SBL has evolved as a way to promote quality in nursing education by guiding faculty to develop a student-centred learning environment, and as a creative way to promote quality nursing care through practice-oriented learning. As we discuss the SBL model we will link the model to relevant learning theories and pedagogies. We begin with the importance of creating student-centred learning environments to promote quality nursing education, and then move to a discussion about how using SBL can promote quality nursing care by fostering practice-oriented learning and focusing students' attention on the human health experience. We propose that SBL can be considered as one example of an integrative pedagogy for learning how to nurse. Next, we describe our experiences with constructing practice stories from a nursing perspective, provide the reader with a brief description of the development and evolution of the SBL model, and introduce the model in some detail. Finally, we conclude with what we have learned from using the SBL model in our undergraduate nursing program and from both formal and informal evaluations.

\section{Creating Student-centred Learning Environments}

SBL decentralizes the educator and promotes active engagement while fostering self-directed learning. The educator facilitates learning, while the learners lead a collaborative learning process. SBL provides a pedagogically oriented map, or framework, for faculty to use to guide the learning process through various steps. "Regurgitating facts is replaced by discovering what it is like to find personal meaning in learning and, vicariously, to own knowledge" (Young, 2007, p. 165). SBL then guides faculty in letting students learn relative to a specific substantive area of nursing practice. Student-centred learning parallels the shift in nursing practice from nurse-centred to patient-centred care by attending to lived experience and facilitating a collaborative process (Young \& Maxwell, 2007).

SBL is a strategy that requires students to learn how to learn nursing, to think critically, and to attend to emotion as a source of self-knowledge and impetus for inquiry. As a form of engaged, experiential learning, SBL enables learning to be personalized, thus making it relevant and meaningful for learners. Built into the SBL framework is participatory dialogue, which helps build learning communities and communities of practice (Amina \& Roberts, 2008; Andrew et al. 2008; Wenger et al. 2002). SBL also provides students with opportunities to reflect on nursing practice and on how they learn, essential skills for life-long learning. In the Carnegie report on transforming nursing education, Benner, Sutphen, Leonard, and Day (2010) identified the ultimate goal for nursing education as developing "life-long learners with the disposition and skills to be reflexive practitioners and expert learners" (p. 4).

\section{Using SBL to Promote Quality Nursing Care}

SBL is a teaching/learning strategy that strengthens learners' capacities to provide quality nursing care. Since about the year 2000, the movement to strengthen quality care has gained momentum. Health professional education is implicated as a key contributor to advancing quality care (Institute of Medicine, 2003). Key documents identify the pillars of quality health 
professional education as client-centred care, inter-professional education, teamwork and collaborative learning, knowledge mobilization and evidence-based practice, awareness of the limits of one's knowledge as a foundation for reflective practice and life-long learning, and mastery of a field of practice (Benner et al. 2010; Council of Ministers of Education, Canada, 2007; Institute of Medicine, 2003; QSEN Institute, 2013; Sherwood, 2012). SBL integrates essential factors of education for health care professionals to ensure that educational strategies prepare health professionals who have the capacity to provide quality care.

\section{Fostering Practice Oriented Learning}

Stories from practice are powerful tools for helping students understand client's perspectives and experiences, for making sense of their own nursing practice, and for engaging learners in focused practice learning (Diekelman \& Ironside, 2003; Ironside \& Hayden-Miles, 2012). Story writing for SBL invites learners to compose stories that elicit emotion as a way of assisting them to tap into the emotional dimension of nursing, thereby fostering the development of linguistic and intrapersonal intelligence (Gardner, 1993, 1999; Young, 2007). Narrative pedagogies such as SBL have been used by nurse educators, and include both written and spoken stories that attend to personal experience and context (Brown \& Rodney, 2007). SBL uses stories to introduce concepts and content in context. This enables students to appreciate the link between theory and practice by promoting dialogue between theoretical or abstract knowledge and the particular nursing practice situation.

\section{Narrative Pedagogies}

Narrative pedagogies focus students' attention on the human health experience by enabling the exploration of different perspectives, experiences, and emotional responses. Stories can make visible the concerns of the patient, family, and nurse, the context for care, and how clinical situations change or unfold over time; thus helping learners understand clinical reasoning as a complex, unfolding process. Students can also learn to challenge conventional wisdom and construct new knowledge as they actively engage with stories (Grendell, 2011; Ironside \& Hayden-Miles, 2012; McAllister et al. 2009). Narrative pedagogies also require collaboration as learners and teachers work together to understand the meaning and nursing implications of a client or nursing practice story. A variety of strategies may be used for narrative pedagogies, including story-telling, written stories, dramatic scripts, and stories recorded online or in film/video productions. Some nurse educators have documented the power of stories to support pedagogies of integration (Ironside, 2006; Brown et al. 2008). SBL is a narrative pedagogy that blends content with process to foster the integrative learning of nursing.

\section{Developing Pedagogies of Integration}

In the Carnegie report, Benner et al. (2010) identified three broad apprenticeships for educating nursing students including: nursing and scientific knowledge, clinical reasoning and skilled know-how, and ethical comportment and identity formation. By apprenticeships, these authors are referring to "a range of integrative learning required by any professional" (p. 25). This important report on transforming nursing education also identified four essential shifts needed in thinking and approach to nursing education, including: (1) shifting from a focus on covering 
decontextualized knowledge to an emphasis on "teaching for a sense of salience, situated cognition, and identifying action in particular clinical situations" (p. 89); (2) better integration of classroom and clinical teaching; (3) more emphasis on clinical reasoning; and, (4) an emphasis on identity formation rather than socialization. In short, they are recommending pedagogies of integration (Tanner, 2008).

SBL helps students learn to attend to cues embedded in practice stories and learn to recognize their significance, which has been described by Benner et al. as developing a "sense of salience" (Benner et al. 2009). SBL also guides students through participatory dialogue with other learners as they engage in collaborative learning conversations about realistic clinical situations while pondering the limits of their clinical knowledge and identifying resources for learning. Thus, learners begin to develop habits foundational to excellence in clinical reasoning. While engaged in the SBL process, students are provided with a safe setting to practice and/or reflect on their clinical decision making skills and the appropriateness of the care planned or previously provided. Benner et al. stress the importance of providing students with "intellectual and moral challenges of reasoning about real patient situations" (2010, p.77). As such, SBL provides opportunities for serious engagement with the practice of nursing and guides students to learn to 'think like a nurse'.

\section{Constructing Practice Stories from a Nursing Perspective}

Stories may be written by educators, students, and/or nurses currently working in practice settings. Students and practising nurses may need guidance to write stories that reflect everyday nursing work. Students often find it useful to write about a practice situation that did not 'have closure' for them. The SBL exercise then becomes a tool for bringing closure to what can be a highly emotional experience for a student nurse. SBL used in this way is a strategy not only for "integrating clinical and classroom learning" (Benner et al. 2010, p. 6), but also for fostering emotional intelligence in learners by enabling them to revisit an emotionally challenging clinical experience and develop emotional coping skills. For example, in one course taught by Lynne Young several students faced patients' deaths in clinical experiences where the clinical instructors were unable to adequately support the students. These students chose to use the SBL exercise to explore their experiences and bring closure to what for them was unfinished business. Providing learning that strengthens coping is an element of fostering the development of emotional intelligence, an important goal for nurse educators (Aradilla-Herrero et al. 2013).

Stories are generally written in the first person and involve few actors (one to three works well). SBL also creates space for story telling (rather than writing) and stories can be audio-recorded or guests can be invited to class to share their personal stories. In addition, short video-clips or stories posted on the internet and/or stories in books can be used with the SBL model. More information on story writing is included in Young's (2007) chapter on SBL (Teaching Nursing: Developing a student-centred learning environment).. 


\section{Development and Evolution of the SBL Model}

SBL incorporates elements of narrative pedagogy, case method teaching (CMT), and problembased learning (PBL) to encourage self-directed learning and student engagement. Young (2007) noted that CMT is a pedagogical strategy that uses stories to set learners up to explore "What are the BIG questions?" related to the case story. Thus, learners are guided to engage with unseen influences on the care situation, for example, the impact of overarching ideologies such as the economic/productive ideology (Wasserman, 1994). This strategy, derived from the CMT tradition, is powerful in revealing ethical issues related to the case story. PBL was developed for learning about clinical medicine by physicians and educators at McMaster University to combine science and learning (Neufeld \& Barrows, 1974). In PBL the problem is posed as a clinical case and requires learners to discover what they need to know to address a practice related problem.

PBL requires that learners reflect on what they know and do not know about the problem, thus learners develop the habit of mind to be clear about the limits of their knowledge relative to a clinical problem (Woods, 1994). PBL is theoretically grounded in the work of Dewey (1963/1938), who proposes that learning occurs when learners are required to think through a problem. Through accessing resources to address the problem, the learner is expected to develop skills with information literacy. These elements of PBL are woven into SBL.

The SBL model differs from PBL in three ways: (1) using stories or narratives rather than decontextualized cases, (2) drawing particular attention to contextual issues, including socioeconomic, ethical and political factors, and (3) presenting learning in a circular and iterative process (Young, 2007). In addition, SBL was linked to nursing ethics by identifying and discussing relevant ethical issues embedded in the particular situation. Further, SBL was developed to provide a nursing lens for learners to identify and discuss a focus for nursing action, a process for negotiating and prioritizing nursing care, and appropriate nursing supports and strategies for informed action. Brown and Hartrick Doane (2007) propose that nurses need to draw on a range of knowledge that enhances "the student's sensitivity and ability to be responsive in particular moments of practice" (p. 109). Theoretical or decontextualized knowledge becomes a "pragmatic tool" used to improve nursing practice (Hartrick Doane \& Varcoe, 2015).

\section{Overview of the SBL Model}

The student-centred orientation of SBL aligns with the philosophical principles of client-centred nursing (Young \& Maxwell, 2007) and a caring curriculum (Bevis and Watson, 1989; Hills and Watson, 2011). The inclusion of attention to socioeconomic and political factors is congruent with emancipatory pedagogies (Hills \& Watson, 2012; Chinn \& Kramer, 2011), relational inquiry (Hartrick Doane \& Varcoe, 2015), and nursing practice informed by the social determinants of health $(\mathrm{SDOH})$. SBL is one strategy that can be used to bridge between the classroom and the clinical setting and, as mentioned previously, is a strategy to help students integrate what they are learning into their thinking about nursing. Group learning also enables learners to develop competencies for co-learning and engaging in clinical reasoning as members of professional and interprofessional teams. 
Since SBL begins with a story of lived experience that captures emotion rather than a problematized case, this strategy aligns well with the philosophical principles that underpin nursing practice: respect for lived experience, caring as a partnership, the need to mobilize strengths of individuals, families, communities, and the health care team (Gottleib, 2013), and critical appraisal of health-related contexts (Hartrick Doane \& Varcoe, 2015). In short, nurses need to think about the patients/clients/people as storied lives rather than problem cases. SBL proceeds in a circular rather than linear manner; a way of thinking that is characteristic of relational caring and understanding lived experience in context. Since nurses work with strengths rather than problems, the model is more congruent with nursing than "problem-based" learning models.

\section{The Outer Circle: Participatory dialogue and critical appraisal of textual/professional information.}

SBL requires active engagement and small group work for brainstorming, critical appraisal, and debriefing. Sharing stories can also help develop the skills needed for nurse-to-nurse consultation as the story makes the "lesson" embedded in the story come alive for the learner. It is important for students to participate actively in group discussions. Students also act as facilitators of the discussion by encouraging their peers to think more deeply by asking critical questions or providing comments that are "food for thought". Through the story, students work together to understand the lived experience of the patient/client/person and the nurse/other health team member. Critical appraisal skills are at the heart of evidence informed nursing practice and include critically examining the scientific merit and practical value of the information being used to inform decision making (Hopp \& Rittenmeyer, 2012). Students learn to retrieve and critically analyze information available to them in peer reviewed articles, websites, and textbooks available through the library and on the internet.

The Inner Circle: The process or phases of $S B L$.

SBL begins (Phase 1) and ends (Phase 6) with attending to the story, reflecting the circular nature of clinical decision making in nursing. Phase two focuses on what is going on in this particular situation/context. Here students share their interpretations of the story with peers and start to identify the person's strengths or personal health resources and the relevant health challenges, issues, and concerns. Next, each learner is invited to reflect on their own learning needs. Learners are required to participate in their own learning by identifying the limits of their knowledge, identifying knowledge gaps, addressing those gaps by retrieving current, reliable, and relevant information, evaluating the information available to them, and by sharing their new knowledge with the group members. This phase concludes with identifying the "Big Questions" (ethical or socio-political) that the nurse must deal with in this particular situation. Examples include: What power relations are operating in this context? Are there concerns about the material and/or social resources needed for health (health inequities)? Is informed decision making a concern?

Phase three involves identifying patterns of wholeness and disruption (Newman, 1999) and ensuring that the context of health and health care is explored fully and critically. For example, strength-focused assessment (Gottleib, 2013) can be the lens used when students engage with and identify patterns of wholeness and disruption in the story (Young, 2007). 
Phase four focuses on identifying and imagining the nursing support and potential resources or referrals that might be appropriate for this situation. Here students are encouraged to draw on nursing knowledge to inform their actions/ recommendations and make the links with evidence informed nursing practice. Searching nursing journals for scholarly papers and examining relevant clinical practice guidelines also helps students to identify recommended nursing approaches and actions.

The SBL process concludes with learners reflecting on what they have learned about learning and nursing. In phase five learners reflect on what they have learned from this particular story and in their shared discussions. Learners are also encouraged to reflect on the learning process and its relevance to their development as a registered nurse. "Reflection helps access and build on experiential or tacit knowledge, as well as other forms of knowledge development" (Sherwood \& Horton-Deutsch, 2012, p. 6). Why ask learners to reflect on their learning? Schon (1987) posited that learners develop as professionals and persons as they reflect on past events, a process labelled reflection-on-action. Nursing has long used critical reflection as a pedagogical strategy to foster intellectual development (Smith, 2011). Thus, reflection is included as part of the SBL process to foster personal, professional, and intellectual development. 


\section{A Story-Based Learning: Blending Content and Process to Learn Nursing}

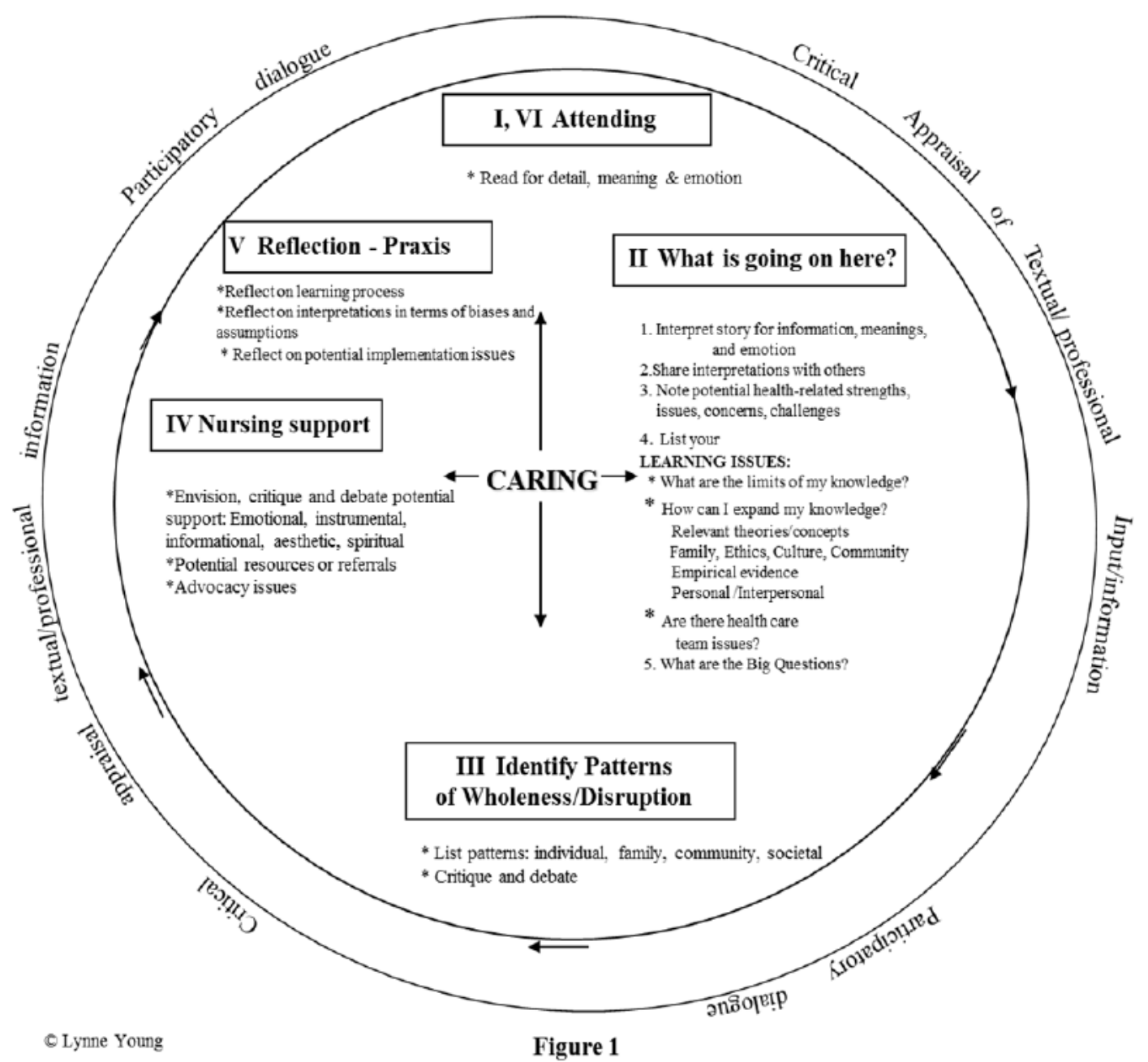

\section{SBL as a Form of Simulation for use with Professional and Interprofessional Teams}

Institutionally-related issues may be a barrier to interprofessional learning during nursing education programs. Stories can be written from different standpoints, including the standpoint of the person/family member, the nurse, or another member of the interprofessional health care team. We have also used SBL with graduate nursing students who frequently construct stories where conflict arises in interprofessional practice contexts. For experienced professional nurses and/or advanced practice nurses, SBL becomes an important way to benefit from peer consultation that frequently focuses on leadership for interprofessional collaboration and conflict transformation (Chinn, 2013). Using stories that speak to how interprofessional teams work together to provide quality, patient-centred, evidence informed care can strengthen nursing students' competencies for interprofessional collaboration (Pesut, 2012). 


\section{What we have Learned: Challenges and Opportunities}

In our early evaluations, SBL was noted to be effective for helping students shift their focus beyond the biomedical perspective while integrating the core content of the nursing curriculum (Young, 2007). In curriculum reviews SBL was noted to be relevant for learning about nursing in a variety of contexts, including hospitals, community, home, and residential care settings. Faculty suggested that SBL could be introduced earlier in the curriculum, rather than only in upper level courses, because of its emphasis on group learning and the development of skills for information literacy and clinical reasoning.

Challenges with implementing SBL as a pedagogical strategy have included selecting stories written at the appropriate level of complexity (scaffolding knowledge) and guiding the learning of students who have little previous experience with active engagement in their educational programs. Although the model provides a framework to facilitate the creation of student-centred learning environments, faculty development was also identified as a critical component of the implementation of SBL in a school of nursing (Young, 2007). One of the challenges identified for faculty using SBL is to 'give up' being the expert and instead develop the capacity to guide learners in leading their own learning by providing a wide range of resources and asking carefully worded questions.

\section{Summary and Conclusions}

SBL sensitizes learners to: identify their own learning needs, build on what they have already learned in the curriculum and in their life experiences, develop information literacy, recognize personal, interpersonal, and health team issues, recognize ethical, socioeconomic and political issues, develop the clinical reasoning /decision making skills needed for nursing, and imagine possibilities for mobilizing strengths, addressing health inequities, and identifying appropriate nursing actions for nursing practice situations. SBL fosters collaborative participatory learning and helps to build models for professional networks and communities of practice.

SBL is founded on what is currently known about effective pedagogical approaches for health professional education. SBL is congruent with current recommendations on transforming nursing education by providing a way to integrate classroom and clinical learning. Further, SBL provides a useful framework to guide faculty in shifting toward student-centered approaches to learning and teaching. SBL has the potential to help nursing students articulate nurses' contributions to the health care team and develop competencies for interprofessional practice. Finally, SBL is designed to develop in learners a habit of mind for clinical reasoning, reflective practice, and the delivery of quality nursing care. 


\section{References}

Amina, A., \& Roberts, J. (2008). Knowing in action: Beyond communities of practice. Research Policy, 37, 353-369.

Andrew, N., \& Tolson, D., \& Ferguson, D. (2008). Building on Wenger: Communities of practice in nursing. Nurse Education Today, 28, 246-252

Aradilla-Herrero, A., Tomás-Sábado, J., \& Gómez-Benito, J. (2013). Associations between emotional intelligence, depression and suicide risk in nursing students. Nurse Education Today, in press corrected proof, DOI 10.1016/j.nedt.2013.07.001

Benner, P., Sutphen, M., Leonard, V., \& Day, L. (2010). Educating nurses: A call for radical transformation. San Francisco CA: Jossey-Bass.

Benner, P., Tanner, C., \& Chesla, C. (2009). Expertise in nursing practice: Caring, clinical judgment and ethics (2nd ed.). New York: Springer Publishing.

Bevis, E.O., \& Watson, J. (1989). Toward a caring curriculum: A new pedagogy for nursing. Sudbury MA: Jones \& Bartlett.

Brown, H., \& Hartick Doane, G. (2007). From filling a bucket to lighting a fire: Aligning nursing education and practice. In L.E. Young \& B.L. Paterson (Eds.). Teaching Nursing:

Developing a student-centered learning environment (pp. 97-118). Philadelphia: Lippincott, Williams \& Wilkins.

Brown, H., \& Rodney, P. (2007). Beyond case studies in practice education: Creating capacities for ethical knowledge through story and narrative. In L.E. Young \& B.L. Paterson (Eds.). Teaching Nursing: Developing a student-centered learning environment (pp. 141-163). Philadelphia: Lippincott, Williams \& Wilkins.

Brown, S. T., Kirkpatrick, M. K., Mangum, D., \& Avery, J. (2008). A review of narrative pedagogy strategies to transform traditional nursing education. Journal of Nursing Education, 47(6), 283-286.

Chinn, P.L. (2013). Peace and Power: New directions for building community (8th ed.). Burlington MA: Jones \& Bartlett Learning.

Chinn, P.L. \& Kramer, M.K. (2011). Integrated theory and knowledge development in nursing ( $8^{\text {th }}$ ed.). St. Louis, MO: Elsevier/Mosby.

Council of Ministers of Education Canada. (2007) Ministerial Statement on Quality Assurance of Degree Education in Canada: Canadian Degree Qualifications Framework. Retrieved Oct 8, 2013 from http://www.cicic.ca/docs/cmec/QA-Statement-2007.en.pdf

Dewey, J. (1963/1938). Experience and education. New York: Collier Books. Diekelmann, N. \& Ironside, P.M. (Eds.). (2003). Interpretive studies in healthcare and the human sciences (Vol. II). Teaching the practitioners of care: New pedagogies for the health professions. Madison: University of Wisconsin Press.

Gardner, H. (1993). Frames of the mind: The theory of multiple intelligences 10th anniversary edition. New York: Basic Books. 
Gardner, H. (1999). Intelligence reframed: Multiple intelligences for the 21st century. New York: Basic Books.

Gottleib, L. (2013). Strengths-based nursing care: Health and healing for person and family. New York NY: Springer Publishing.

Grendell, R.N. (2011). Narrative pedagogy, technology, and curriculum transformation in nursing education. Journal of Leadership Studies, 4, 65 - 67.

Hartrick Doane, G., \& Varcoe, C. (2015). How to nurse: Relational inquiry with individuals and families in changing health and health care contexts. Baltimore MD: Lippincott, Williams \& Wilkins.

Hills, M., \& Watson, J. (2011). Creating a caring science curriculum: An emancipatory pedagogy for nursing. New York: Springer Publishing.

Hopp, L., \& Rittenmeyer, L. (2012). Introduction to evidence-based practice: A practical guide for nursing. Philadelphia, PA: F.A. Davis.

Institute of Medicine of the National Academies. (2003). Health professions education: A bridge to quality. Washington DC: The National Academies Press.

Ironside, P. M. (2006). Using narrative pedagogy: Learning and practicing interpretive thinking. Journal of Advanced Nursing, 55, 478-486.

Ironside, P., \& Hayden-Miles, M. (2012). Narrative pedagogy: Co-creating engaging learning experiences with students. In G. Sherwood \& S. Horton-Deutsch (Eds.) Reflective practice: Transforming Education and Improving Outcomes (pp. 135-148). Indianapolis IN: Sigma Theta Tau International.

McAllister, M., Tracey, J., Gray, M., Williams, L., Barnes, M., Allan, J., \& Rowe, J. (2009). Adopting narrative pedagogy to improve the student learning experience in a regional Australian University. Contemporary Nurse, 32, 156-165.

Neufeld, V.R., \& Barrows, H.S. (1974). The "McMaster Philosophy": An approach to medical education. Journal of Medical Education, 49, 1040-1050.

Newman, M. A. (1999). The Rhythm of Relating in a Paradigm of Wholeness. Image: the Journal of Nursing Scholarship, 31, 227-230.

QSEN Institute: Quality and Safety Education for Nursing (2013). Quality improvement resources. Available from: http://qsen.org/faculty-resources/quality-improvement-resources-2/

Pesut, D. J. (2012). Reflecting as a team: Issues to consider in interprofessional practice. In G. Sherwood \& S. Horton-Deutsch (Eds.) Reflective practice: Transforming Education and Improving Outcomes (pp. 265-282). Indianapolis IN: Sigma Theta Tau International.

Schon, D. (1987). Educating the Reflective Practitioner. Toward a New Design for Teaching and Learning in the Professions. San Francisco: Jossey-Bass.

Sherwood, G. (2012). Driving forces for quality and safety: Changing mindsets to improve health care. In G. Sherwood and J. Barnsteiner (Eds.). Quality and safety in nursing: A competency approach to improving outcomes (pp. 3-12). Chichester, West Sussex: WileyBlackwell. 
Sherwood, G., \& Horton-Deutsch, S. (2012). Turning vision into action. In G. Sherwood \& S. Horton-Deutsch (Eds.) Reflective practice: Transforming Education and Improving Outcomes (pp. 3-19). Indianapolis IN: Sigma Theta Tau International.

Smith, E. (2011). Teaching critical reflection. Teaching in Higher Education, 16, 211-223. Tanner, C.A. (2008). Clinical judgment and evidence-based practice: toward pedagogies of integration. The Journal of Nursing Education, 47, 335.

Wasserman, S. (1994). Introduction to case method teaching: A guide to the galaxy. New York: Teachers College

Wenger, E., McDermott, R., \& Snyder, W.M. (2002). Cultivating Communities of Practice, Harvard Business School Press: Boston, Massachusetts

Woods, D. (1994). Problem-Based Learning: How to gain the most from PBL. McMaster University. Hamilton ON: Donald Woods.

Young, L.E. (2007). Story based learning: Blending content and process to learn nursing. In L.E. Young \& B.L. Paterson (Eds.). Teaching Nursing: Developing a student-centered learning environment (pp. 164-188). Philadelphia: Lippincott, Williams \& Wilkins.

Young, L.E. \& Maxwell, B. (2007). From Rote to Active Learning: Constructivism in the context of teaching theories. In Young, L.E. \& B. Paterson (Eds.) Teaching Nursing: Developing a student-centered learning environment, (pp. 1-25). Philadelphia, PA: Lippincott, Williams, and Wilkins. 
Karen MacKinnon PhD RN is currently an Associate Professor in the School of Nursing at the University of Victoria where she teaches both undergraduate and graduate nursing students. Her program of research explores the social organization of health experiences and the work of childbearing women and nurses who provide maternity care for women and their families, with a special focus on rural nursing. Karen also utilizes story-based learning as a pedagogical strategy in her teaching to help keep the health experiences of women and nurses embodied and contextualized. She is passionate about nursing work that addresses health inequities and promotes social justice.

Lynne E. Young PhD RN: is a Professor in the School of Nursing at the University of Victoria. Lynne has a longstanding interest in teaching and learning in nursing. She is co-editor of a book used widely by nurse educators entitled: "Teaching Nursing: Developing a student-centered learning environment". Dr. Young is the recipient of two awards for teaching - the 2012 CASN Award of Excellence for Teaching and the 2013 CRNBC Award of Excellence in Nursing Education 